\title{
Zinc Deficiency Inhibits Chlorophyll Synthesis and Gas Exchange in 'Stuart' Pecan
}

\author{
Hening $\mathrm{Hu}^{1}$ and Darrell Sparks ${ }^{2}$ \\ Department of Horticulture, University of Georgia, Athens, GA 30602
}

Additional index words. Carya illinoensis, intercellular $\mathrm{CO}_{2}$, nutrition, photosynthesis,

stomatal conductance

\begin{abstract}
Leaves of 'Stuart' pecan [Carya illinoensis (Wangenh.) C. Koch] with various levels of $\mathrm{Zn}$ deficiency were analyzed for physiological indicators of leaf vigor. Leaf chlorophyll content, stomatal conductance, and net photosynthesis were adversely affected by $\mathrm{Zn}$ deficiency. In leaves with severe $\mathrm{Zn}$ deficiency, each of these indicators increased 3- to 5-fold with a doubling of leaf $\mathrm{Zn}$ concentration, but stabilized as leaf $\mathrm{Zn}$ approached the sufficiency range $\left(14 \mu \mathrm{g} \cdot \mathrm{g}^{-1}\right)$. High intercellular $\mathrm{CO}_{2}$ associated with low net photosynthesis indicates that stomatal aperture was not the cause of the reduction of net photosynthesis under $\mathrm{Zn}$ deficiency.
\end{abstract}

Inadequate $\mathrm{Zn}$ levels severely limit crop productivity in pecan (Brooks, 1964; Worley et al., 1972). Zinc deficiency remains a recurrent problem in pecan orchards in spite of extensive research documenting critical leaf values (Amling, 1965; Sparks and Payne, 1982; Worley et al., 1972) as well as methods of prevention and correction (Payne and Sparks, 1932; Sparks, 1976; Worley et al., 1981) for proper growth of the pecan tree. The morphological abnormalities that occur in both the vegetative and reproductive growth of $\mathrm{Zn}$-deficient trees have been described $(\mathrm{Hu}$ and Sparks, 1990; Rand, 1922). However, the impact of $\mathrm{Zn}$ deficiency on the physiology of the pecan tree has not been examined. Photosynthesis would be expected to be affected because chlorosis and distorted leaf growth are prominent symptoms of $\mathrm{Zn}$ deficiency. Our objective was to quantify the effects of $\mathrm{Zn}$ deficiency on chlorophyll concentration and stomatal conductance of pecan leaves and their relationship to photosynthesis.

The study was conducted in a pecan orchard located on the Southeastern Fruit and Tree Nut Laboratory, Byron, Ga., with 'Stuart' trees $\approx \$ 0$ years old. Normal and $\mathrm{Zn}$ deficient shoots were selected from eight trees when degrees of $\mathrm{Zn}$ deficiency could be clearly distinguished (13 May). The shoots were divided into five groups according to rosette and extent of leaf crinkling: 1, rosette; 2 , very severe crinkling but no rosette; 3 , severe crinkling; 4, moderate crinkling limited to apical leaves only; and 5, no visible symptoms of $\mathrm{Zn}$ deficiency.

Net photosynthesis and stomatal conduct-

Received for publication 20 June 1990. Appreciation is expressed to James Stuckey and the Southeastern Fruit and Tree Nut Laboratory, Byron, Ga. for use of trees. The cost of publishing this paper was defrayed in part by the payment of page charges. Under postal regulations, this paper therefore must be hereby marked advertisement solely to indicate this fact.

'Graduate student.

${ }^{2}$ Professor. ante were determined using a LI-COR 6000 portable photosynthetic system with a 4-liter leaf chamber (LI-COR, Lincoln, Neb.). Evaluations were made in mid-August using the apical leaflet of the middle leaf on shoots exposed to the sun. Measurements were made between 9:00 AM and 12:00 noon at a photosynthetic photon flux density of 1860 $( \pm 180) \mu \mathrm{mol} \cdot \mathrm{s}^{-1} \cdot \mathrm{m}^{-2}$, and at ambient atmospheric $\mathrm{CO}_{2}$ levels $(385 \pm 23$ $\left.\mu \mathrm{mol} \cdot \mathrm{mol}^{-1}\right)$. Each leaflet was measured 10 consecutive times on each of the 10 leaves in each category of $\mathrm{Zn}$ deficiency. During the period of measurement, leaf temperature increased $\approx 0.7 \mathrm{C}$, while relative humidity increased $\approx: 1 \%$. Leaf area was determined with a LI-COR 3100 area meter. For the two most severe $\mathrm{Zn}$-deficient groups, intercellular $\mathrm{CO}_{2}$ values, determined with the LI-COR 6000 , were higher for some leaves than ambient $\mathrm{CO}_{2}$ levels even though positive net photosynthetic rates were detected. As a result, intercellular $\mathrm{CO}_{2}$ values were calculated by the method of von Caemmerer and Farquhar (1981). Except for the two most severe Zn-deficient groups, the calculated intercellular $\mathrm{CO}_{2}$ values were within a $2.5 \%$ difference of those determined with the LI-COR 6000 meter.

Leaflet samples for chlorophyll and $\mathrm{Zn}$ analysis were taken on 29 July according to prescribed sampling procedures (Sparks, 1970). Chlorophyll was extracted and determined in the fresh leaflet (Arnon, 1949). Airdried leaflets were oven-dried for $72 \mathrm{~h}$ at $70 \mathrm{C}$, ground, redried, and analyzed for $\mathrm{Zn}$ by inductively coupled plasma argon spectrophotometry (Isaac and Johnson, 1983).

Data were subjected to regression analysis (Helwig and Council, 1979). In cases of nonlinear models, the $r^{2}$ values were calculated as 1.0 minus the ratio of the residual sum of squares to the corrected total sum of squares (Ware et al., 1982).

Severity of $\mathrm{Zn}$ deficiency was inversely related to $\mathrm{Zn}$ concentration in the leaf. Zinc concentration in leaves with rosette, very severe deficiency, severe deficiency, moderate deficiency, and no visible symptom of $\mathrm{Zn}$ deficiency was $3.8,4.4,4.9,6.1$, and 14.3 $\mu \mathrm{g} \cdot \mathrm{g}^{-1}$, respectively. The values of 6.1 and 14.3 associated with $\mathrm{Zn}$ deficiency and no deficiency, respectively, are close to those reported by Finch (1936) and Finch and Kinnison (1933). The leaf $\mathrm{Zn}$ concentration of $\approx 14 \mu \mathrm{g} \cdot \mathrm{g}^{-1}$ is also the value associated with normal fruit growth (Hu and Sparks, 1990).

Chlorophyll concentration increased with leaf $\mathrm{Zn}$ (Fig. 1), corresponding to morphological observations that leaf chlorosis decreases with increasing leaf $\mathrm{Zn}$. The response curve of stomatal conductance to leaf $\mathrm{Zn}$ concentration (Fig. 1) was very similar to that for chlorophyll as indicated by the correlation $(r=0.976)$ between the two factors. As expected from the chlorophyll and stomatal conductance response curves, net photosynthesis (Fig. 2) was also very sensitively regulated by $\mathrm{Zn}$ when $\mathrm{Zn}$ was within the deficiency range. The response of intercellular $\mathrm{CO}_{2}$ was the reverse of net photosynthesis and decreased as leaf $\mathrm{Zn}$ increased (Fig. 2). The response of net photosynthesis and intercellular $\mathrm{CO}_{2}$ had not stabilized at $\mathrm{Zn}$ rates of $14 \mu \mathrm{g} \cdot \mathrm{g}^{-1}$, in contrast to chlorophyll and stomatal conductance, which were near maximum at $\mathrm{Zn}$ rates of $14 \mu \mathrm{g} \cdot \mathrm{g}^{-1}$ (Fig. $1)$.

Net photosynthesis increased and intercellular $\mathrm{CO}_{2}$ decreased with chlorophyll concentration (Fig. 3). A first order derivative indicated a two-phase increase in net photosynthesis with chlorophyll. Thus, the changes in net photosynthesis were more sensitive to the changes in chlorophyll content at low and high chlorophyll contents than at intermediate levels. This differential response may be associated with the transition from disintegrated chloroplasts in severe $\mathrm{Zn}$ deficiency to normal chloroplasts in nondeficient leaves (Rand, 1922). Likewise, a report in kidney bean plant (Phaseolus vulgaris L.) with varying chlorophyll contents at different stages of greening, demonstrated a twophase increase of photochemical reactions

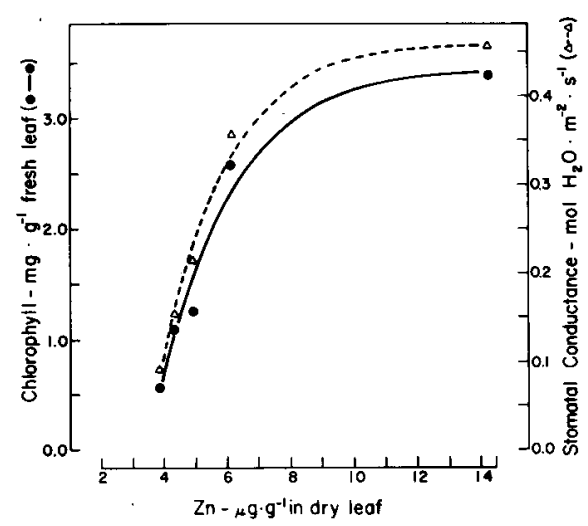

Fig. 1. Chlorophyll concentration and stomatal conductance of 'Stuart' pecan leaves vs. $\mathrm{Zn}$ concentration in the leaf. The relationship of chlorophyll vs. Zn and stomatal conductance vs. Zn follows Mitscherlich's plant growth model as follows: $\mathrm{Y}=3.4575\left(1-4.278 \mathrm{e}^{-0.4203 \mathrm{x}}\right)$, $r^{2}=0.958 ;$ and $\mathrm{Y}=0.4621(1-$ $\left.5.0906 \mathrm{e}^{-0.4770 \mathrm{x}}\right), r^{2}=0.931$; respectively, $P$ $\leq 0.01$. 


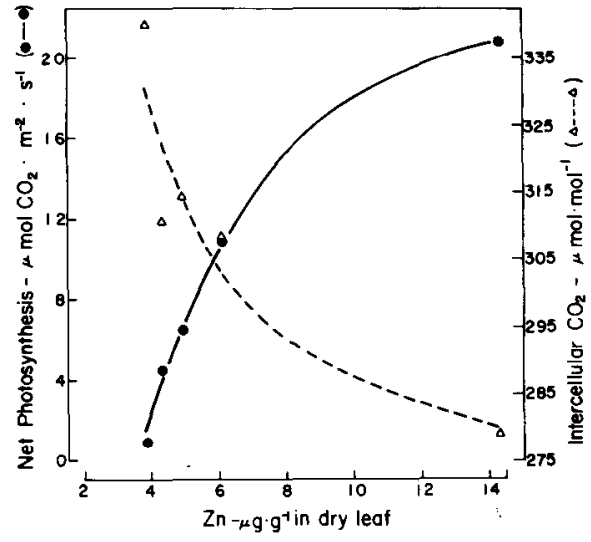

Fig. 2. Relationship of net photosynthesis and intercellular $\mathrm{CO}_{2}$ in 'Stuart' pecan leaves to $\mathrm{Zn}$ in the leaf. The relationship between net photosynthesis and $\mathrm{Zn}$ follows Mitscherlich's plant growth model, $Y=22.1587$ (1 $\left.2.5587 \mathrm{e}^{-0.2637 x}\right), r^{2}=0.965$; while the relationship of intercellular $\mathrm{CO}_{2}$ vs. $\mathrm{Zn}$ is described by an equilateral hyperbola curve, $1 / \mathrm{Y}=$ $0.00377-0.0028841 / \mathrm{X}, r^{2}=0.820 . P \leq$ 0.01 .

with the increase of chlorophyll (Koizumi et al., 1990). The first phase of the increase in chlorophyll content was mainly associated with reaction centers, and the second phase with the formation of light-harvesting pigments

Net photosynthesis increased and intercellular $\mathrm{CO}_{2}$ decreased with increasing stomatal conductance (Fig. 4). Wong et al. (1979) proposed that stomatal aperature was regulated by carbon fixation in mesophyll cells of $\mathrm{N}$ - and P-deficient plants. Their hypothesis was based on the fact that intercellular $\mathrm{CO}_{2}$ remained constant regardless of the severity of these nutrient deficiencies. In our study, intercellular $\mathrm{CO}_{2}$ was not constant and the relationship between photosynthesis and stomatal conductance was nonlinear (Fig. 4). These results suggest that the capacity of stomatal response to carbon fixation may be partially lost under $\mathrm{Zn}$ deficiency. These data also suggest that stomatal aperture is not the mechanism restricting photosynthetic capacity in Zn-deficient pecans. This situation differs from waterstressed plants (Sharkey and Seemann, 1989), where decreased photosynthesis was accounted for by reduced $\mathrm{CO}_{2}$ availability due to stomatal closure.

Limited photosynthesis in $\mathrm{Zn}$-deficient plants may be due to lesions in metabolic pathways regulating photochemical activity and/or carbon reduction. Zinc deficiency resulted in a partially irreversible loss of chloroplast photochemical activity in safflower (Carthamus tinctorius L.) (Pandey and Sharma, 1989) and reduced the Hill reaction in corn (Zea mays L.) (Shrotri et al., 1981). In addition, Zn deficiency reduced carbonic anhydrase activity in peach [Prunus persica (L.) Batsch.] (Basiouny and Bigs, 1976) and pecan (Stir, 1983). Reductions in light and dark reactions of photosynthesis might be expected because $\mathrm{Zn}$ deficiency decreases RNA and protein synthesis (Mazus et al., 1986; Schneider and Price, 1962).

Chlorophyll and stomatal conductance were near maximum when leaf $\mathrm{Zn}$ was $14 \mu \mathrm{g} \cdot \mathrm{g}^{-1}$. Photosynthesis was still increasing at values

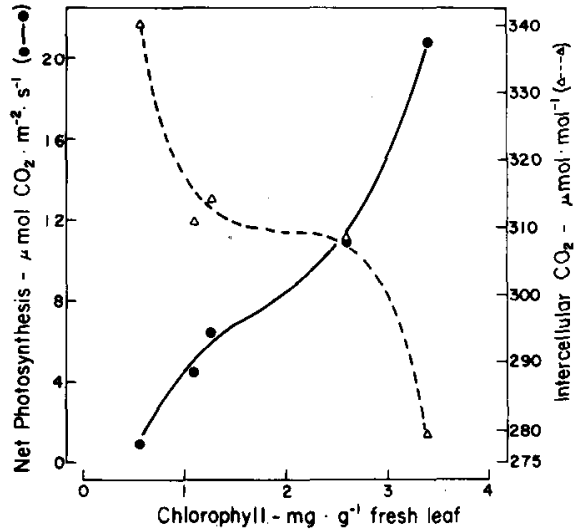

Fig. 3. Net photosynthesis and intercellular $\mathrm{CO}_{2}$ of 'Stuart' pecan leaves as affected by the leaf chlorophyll content. The relationship of. net photosynthesis to chlorophyll and intercellular $\mathrm{CO}_{2}$ to chlorophyll follows third order equations described by $\mathrm{Y}=-7.7693+20.2562 \mathrm{X}$ $-9.7776 \mathrm{X}^{2}+1.8533 \mathrm{X}^{3}, r^{2}=0.980$; and $\mathrm{Y}$ $=397.88-140.592 \mathrm{X}+72.272 \mathrm{X}^{2}$ $12.116 \mathrm{X}^{3}, r^{2}=0.902$, respectively. $P \leq 0.01$.

$<14 \mu \mathrm{g} \cdot \mathrm{g}^{-1}$, but at a diminishing rate. These results indicate that on a shoot basis, optimum leaf $\mathrm{Zn}$ is at some value near $14 \mu \mathrm{g} \cdot \mathrm{g}^{-1}$. However, on a whole-tree or orchard basis, pecan will often respond to leaf diagnostic values $>14 \mu \mathrm{g} \cdot \mathrm{g}^{-1}$. This discrepancy occurs, as previously discussed (Hu and Sparks, 1990), because of the extreme variation in Zn deficiency within and among trees and the method of leaf sampling.

\section{Literature Cited}

Amling, H.J. 1965. Alabama leaf analysis service. Proc. Southeastern Pecan Growers Assn. 58:25-33.

Amen, D.I. 1949. Copper enzymes in isolated chloroplasts polyphenoloxidase in Beta vulgaris. Plant Physiol. 24:1-5.

Basiouny, F.M. and R.H. Biggs. 1976. Photosynthesis and carbonic anhydrase activity in Zn-deficient peaches irradiated with ultraviolet light. HortScience 11:408410.

Brooks, O.L. 1964. Yield response of Stuart pecan to zinc sulfate. Proc. Southeastern Pecan Growers Assn. 57:23-25.

Finch, A.H. 1936. Zinc and other mineral constituents in relation to rosette disease of pecan trees. J. Agr. Res. 52363-376.

Finch, A.H. and A.F. Kinnison. 1933. Pecan rosette: Soil, chemical, and physiological studies. Univ. Ariz. Agr. Expt. Sta. Bul 47.

Helwig, J.T. and K.A. Council. 1979. SAS user's guide. SAS Institute Inc., Cary, N.C.

Hu, H. and D. Sparks. 1990. Zinc deficiency inhibits reproductive development in 'Stuart' pecan. HortScience 25:1392-1396.

Isaac, R.A. and W.C. Johnson. 1983. High speed analysis of agricultural samples using inductively coupled plasma-atomic emission spectroscopy. Spectro. Acta 38B(1-2)277-282.

Koizumi, M., H. Kane, N. Katsura, and K. Inada. 1990. The effect of chlorophyll content on changes of photoehemical reactions in intact kidney bean leaves. Plant Cell \& Env. 13:65-71.

Mazus, B., K.H. Falchuk, and B.L. Vallee. 1986. Inhibition of Euglena gracilis and wheat germ zinc RNA polymerases II by 1, 10-phenanthroline acting as a chelating agent. Biochemistry 25:2941-2945.

Pandey, N. and C.P. Shanna. 1989. Zinc deficiency effect on photosynthesis and transpiration in saf-

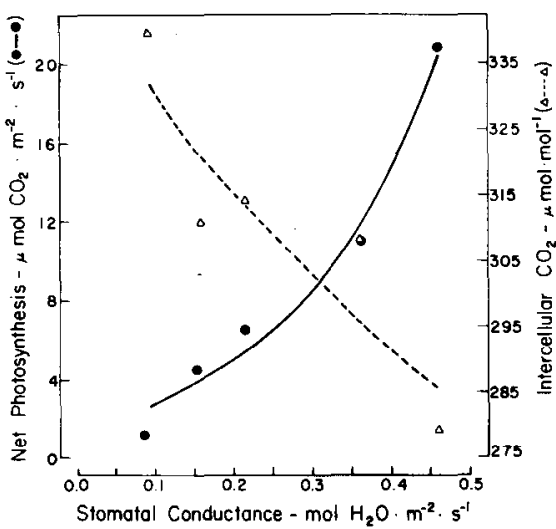

Fig. 4. Relationship of net photosynthesis and intercellular $\mathrm{CO}_{2}$ to stomatal conductance in 'Stuart' pecan. The relationship of photosynthesis to stomatal conductance is. described by $\mathrm{Y}=142.4469 /(1+90.0871 \times 0.002799 \mathrm{X})$ $r^{2}=0.946$; while the relationship of intercellular $\mathrm{CO}_{2}$ to stomatal conductance follows $\sqrt{\mathrm{Y}}$ $=18.5444-3.5988$ X. $r^{2}=0.714 . P \leq 0.01$.

flower and its reversal on making up the deficiency. Indian J. Expt. Biol. 27:376-377.

Payne, J.A. and D. Sparks. 1982. zinc level in pecan leaflets from broadcast and band application over a six-year period. HortScience 17:235-236.

Rand, F.V. 1922. Pecan rosette: Its histology, cytology, and relation to other chlorotic diseases. U.S. Dept. Agr. Bul. 1038.

Schneider, E. and C.A. Price. 1962. Decreased ribonucleic acid levels: A possible cause of growth inhibition in zinc deficiency. Biochim. Biophys. Acts 55:40W08.

Sharkey, T.D. and J.R. Seemann. 1989. Mild water stress effects on carbon-reduction-cycle intermediates, ribulose bisphosphate carboxylase activity and spatial homogeneity of photosynthesis in intact leaves. Plant Physiol. 89:106LL1O65.

Shrotri, C. K., V.S. Rathore, and P. Mohanty. 1981. Studies on photosynthetic electron transport, photophosphorylation and $\mathrm{CO}_{2}$ fixation in zinc deficient leaf cells of Zea mays L. J. Plant Nutr. 3:945-954.

Snir, I. 1983. Carbonic anhydrase activity as an indicator of zinc deficiency in pecan leaves. Plant \& Soil $74: 287-289$.

Sparks, D. 1970. The time to sample leaflets for foliar nutrient analysis of pecan. Proc. Southeastern Pecan Growers Assn. 63:113.

Sparks, D. 1976. zinc nutrition and the pecan-a review. Pecan South 3(2):304-334.

Sparks, D. and J.A. Payne. 1982. Zinc concentration in pecan leaflets associated with zinc deficiency symptoms. HortScience 17:670-671.

von Caemmerer, S. and G.D. Farquhar. 1981. Some relationships between the biochemistry of photosynthesis and the gas exchange of leaves. Planta 153:376387.

Ware, G. O., K. Ohki, and L.C. Moon. 1982. The Mitscherlich plant growth model for determining critical nutrient deficiency levels. Agron. J. 74:8891.

Wong, S. C., I.R. Cowan, and G.D. Farquhar. 1979. Stomata] conductance correlates with photosynthetic capacity. Nature (London) 282:424426.

Wodey, R. E., S.A. Hamron, and R.L. Carter. 1972. Effect of zinc sources and methods of application on yield and leaf mineral concentration of pecan, Carya i[linoensis, Koch. J. Amer. Soc. Hort. Sci. 97:364369

Wodey, R. E., R.H. Litrell, and J.D. Dutcher. 1981. A comparison of zinc injection and zinc implantation for rapid correction of zinc deficiency. Proc. Soutbeastem Pecan Growers Assn. 74:69-71. 